\title{
Heterotopic Salivary Gland Tissue in the Larynx
}

\author{
Rohan Bidaye*, Ashraf Mahmood, Sam Arman and Huw Griffiths \\ Department of ENT, Head Neck Surgery, University Hospitals Birmingham, UK
}

\begin{abstract}
Heterotopic Salivary Gland Tissue (HSGT) of the larynx is an extremely rare pathology, with only 8 cases reported in English literature. We are reporting 2 cases of HSGT in the larynx which we encountered in our practice. The first one is a unique presentation of a 45 year old female with HSGT in bilateral false vocal cords. While the second case is 50 -year-old male patient with HSGT in the left false vocal cord and subglottic region. With these 2 cases, we would be discussing about the clinical presentation of this rare anomaly and add to the literature.
\end{abstract}

\section{Introduction}

The embryological development of the head and neck region is a complex process with various structures developing from six branchial arches, all migrating simultaneously and growing in proximity to one other. Congenital anomalies are frequently encountered within the head and neck region and often provide a diagnostic challenge to the doctor [1].

Heterotopic Salivary Gland Tissue (HSGT)/ectopic salivary gland tissue /salivary gland choristoma is a rare congenital anomaly in which salivary gland tissue is found outside the major and minor salivary glands. HSGT is found in relation to the sternocleidomastoid muscle as a draining sinus or an asymptomatic nodule [1]. It has also been reported in the middle ear [2], pituitary [3], mandible and the gingival [5].

\section{Case Series}

\section{Case 1}

A 45-year-oldfemale patient presented with a history of hoarseness of voice and throat discomfort for 3 months. There was no history of trauma, reflux, smoking or other red flag symptoms suggestive of malignancy. Flexible endoscopic examination revealed cystic lesions in the anterior $1 / 3^{\text {rd }}$ of the false vocal folds, bilaterally. The true vocal folds were normal with no phonatory gap. There was evidence of dysphonia plica ventricularis on phonation at higher notes. The rest of the head and

OPEN ACCESS

*Correspondence:

Rohan Bidaye, Department of ENT, Head Neck Surgery, University Hospitals Birmingham, UK, E-mail: rrbidaye@gmail.com Received Date: 30 Mar 2021

Accepted Date: 30 Apr 2021

Published Date: 04 May 2021

Citation:

Bidaye R, Mahmood A, Arman S, Griffiths H. Heterotopic Salivary Gland Tissue in the Larynx. Am J Otolaryngol Head Neck Surg. 2021; 4(3): 1129.

Copyright $\odot 2021$ Rohan Bidaye. This is an open access article distributed under the Creative Commons Attribution

License, which permits unrestricted

use, distribution, and reproduction in any medium, provided the original work is properly cited. neck examination was unremarkable.

To confirm the diagnosis, the larynx was examined under General Anesthesia (GA) and the larger cystic lesion on the left false vocal fold was excised and sent for Histopathological analysis. The right false vocal fold lesion was not excised to avoid an anterior glottic web formation.

The histopathology specimen was reported as seromucinous salivary gland tissue (Figure 1). An MRI scan of the neck was performed after the surgery to rule out the presence of similar lesions in the rest of the larynx. The patient followed up with our speech and language therapy team for voice therapy. Her hoarseness of voice improved over time with therapy. However, 2 years after the initial episode, she represented with a worsening of her voice. Examination of the larynx revealed an increase in size of the right false vocal fold lesion (Figure 2). After a thorough discussion about the options with the patient, a repeat Microlaryngoscopy with excision of the right false vocal fold lesion was performed under GA. The excised specimen was reported as seromucinous salivary gland tissue. The $2^{\text {nd }}$ surgery was complicated by the formation of a granuloma at the site of excision. This required a repeat Microlaryngoscopy and excision under GA and was confirmed to be inflammatory granulation tissue. There was an immediate relief in symptoms after the last procedure. She has been on follow up since and there is no recurrence in the last 24 months.

\section{Case 2}

A 50-year-oldmale patient presented with a history of persistent cough and globus sensation for 5 months. Flexible endoscopy of the larynx revealed a small cystic lesion of the left false vocal fold. The rest of the head and neck examination was unremarkable.

Barium swallow and a chest X-ray were reported as normal. An examination of the larynx was 


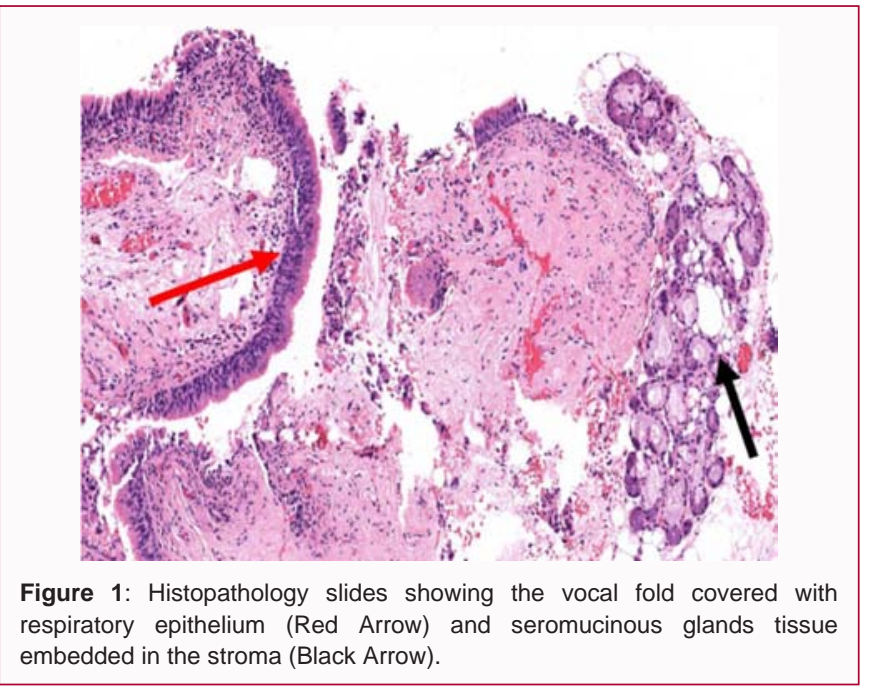

embedded in the stroma (Black Arrow)

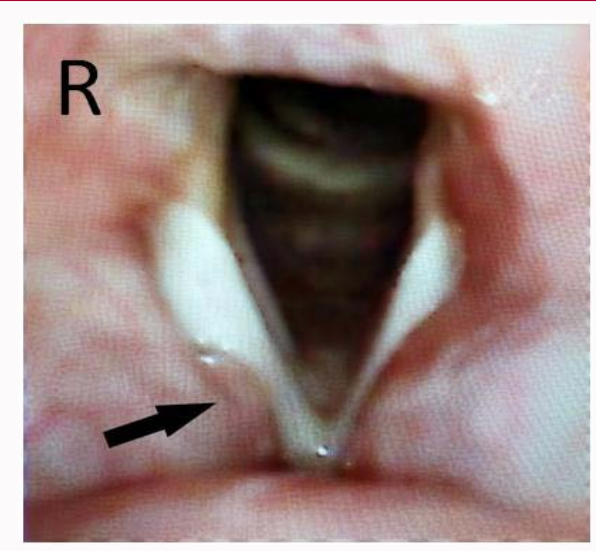

Figure 2: Laryngoscopy image before the $2^{\text {nd }}$ procedure showing a right false cord cystic lesion (Black arrow) which was later confirmed as Salivary gland tissue on Histopathology.

performed under general anesthesia which revealed another cystic lesion in the subglottis. Both the lesions from the left false cord and the subglottis were excised and sent for histopathological examination. The patient was prescribed empirical anti-reflux treatment with proton pump inhibitors and alginate. The Speech and Language Therapist taught him cough suppression strategies, vocal hygiene, and de-constriction strategies to relieve the tension in the vocal tract.

The histopathology of both specimens from the left false cord and the subglottis was reported as seromucinous salivary gland tissue. An MRI scan of the neck confirmed complete excision and ruled out similar lesions in and around the larynx. The patient was under follow up with no active symptoms and flexible nasal endoscopic examination until 3 years showed no evidence of recurrence of the lesion. However, at the last examination a new lesion was noticed on the right false cord (Figure 3). The appearance is like the lesions seen previously on the left vocal cord and so likely to be HSGT. We have discussed the possibility of removing this lesion with the patient and are awaiting his decision.

\section{Discussion}

Laryngeal embryogenesis from the mesenchyme of the $4^{\text {th }}$ pharyngeal arch and the endodermal lining of the $4^{\text {th }}$ pharyngeal pouch begins in the $3^{\text {rd }}$ to $4^{\text {th }}$ week of fetal life with the appearance of the respiratory primordium [6]. Absent or irregular growth and

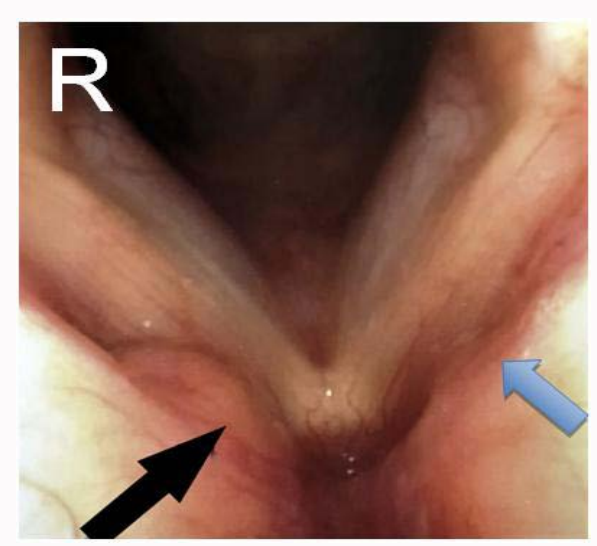

Figure 3: Laryngoscopy image before the proposed $2^{\text {nd }}$ procedure. The black arrow points to the right false cord cystic lesion suspected to be Salivary gland tissue. The Blue Arrow on the Left false cord from where the Salivary gland tissue was previously excised.

abnormal septation of the larynx from adjoining structures such as the pharynx, esophagus and primitive lung can result in varying congenital defects that may occlude the airway [6].

Growth and migration of the salivary glands during the $4^{\text {th }}$ to $6^{\text {th }}$ week of fetal life is a complex process involving the encapsulation of oral epithelium within mesenchymal tissue [7]. Majority of HSGT are found within or close to the parotid gland. This is likely due to the associated development of the cervical lymphatic system during the $12^{\text {th }}$ to $14^{\text {th }}$ week. As the parotid is the only gland with intraglandular and peri-glandular lymph nodes, salivary tissue can become entrapped during encapsulation [7].

Beyond the Parotid and cervical lymph nodes, HSGT has been reported in the middle ear [2], mandible [4], palatine tonsils and parathyroid glands $[7,8]$. Aberrant migration of salivary glands from the oral cavity during embryogenesis likely explains HGST in the mandible and the tonsils [7]. However, HSGT in the lower cervical neck is difficult to ascertain with most theories attributing it to the abnormal development of epithelial tissue associated with the branchial apparatus and primitive foregut [7].

HSGT of the larynx has been reported in only 8 cases in the English literature; with all cases occurring in males and within one of the false vocal cords (Table 1). We are reporting the first case in a female and presenting bilaterally in the false cords and also in the subglottis.

HSGT presents with a wide range of symptoms from hoarseness of voice, globus sensation, and pharyngeal discomfort to sore throat, and persistent coughing. Secretory activity of the salivary tissue is possible and has previously been reported at other sites in the neck [9-16]. This could explain the presenting symptoms of persistent cough and throat clearing.

It is difficult to differentiate HSGT from a Laryngeal cyst based on the clinical picture. Due to the wide differential diagnosis and possible pathologies, obtaining a tissue sample for histopathological examination is crucial to confirm the diagnosis and outline the next treatment plan. Even though none of the reported cases showed any evidence of malignancy, these lesions are composed of salivary tissue and theoretically are susceptible to the same benign and malignant pathological conditions of other salivary glands [16]. In the early stages, salivary gland tumors may not present with obvious symptoms 
Table 1: List of the 10 cases of HSGT published in literature.

\begin{tabular}{|c|c|l|l|l|l|}
\hline Sr No. & Age & \multicolumn{1}{|c|}{ Sex } & \multicolumn{1}{|c|}{ Symptoms } & \multicolumn{1}{|c|}{ Year } & \multicolumn{1}{|c|}{ Lead Author } \\
\hline 1 & 56 & Male & Hoarseness & Laryngeal Vestibule & Kruk-Zagajewska et al. [9] \\
\hline 2 & 70 & Male & Cough & False vocal cord & Yamanaka et al. [10] \\
\hline 3 & 65 & Male & Pharyngeal Discomfort & False vocal cord & Yamanaka et al. [10] \\
\hline 4 & 80 & Male & Hoarseness \& Coughing & Left false vocal cord & Kempf et al. [11] \\
\hline 5 & 75 & Male & Hoarseness & False vocal cord & Yamaguchi et al. [12] \\
\hline 6 & 43 & Male & Hoarseness \& Coughing & Left false vocal cord & Yilmaz et al. [13] \\
\hline 7 & 46 & Male & Sore throat & Left false vocal cord & Tajima et al. [14] \\
\hline 8 & 56 & Male & Hoarseness & Left false vocal cord & Valentino et al. [15] \\
\hline 10 & 45 & Female & Hoarseness of voice & Left false vocal cord and subglottis & 2019 \\
\hline
\end{tabular}

due to slow submucosal spread [17]. The predominant pathologic diagnosis in minor salivary glands is adenoid cystic carcinoma $[18,19]$ Also, of note, $60 \%$ of patients with mucoepidermoid carcinomas of the larynx are localized in the supraglottic area [20]. But there is no evidence to prove that the malignant pathology originated from an initial ectopic benign tissue. We would recommend performing an MRI scan of the neck especially if the lateral extent of the lesion into the ventricle could not be visualized. This may also help in ruling out a malignant pathology. It is also important to keep a vigilant follow up for recurrence of any lesions.

\section{Conclusion}

- $\quad$ Heterotopic Salivary Gland Tissue (HSGT) can present as a benign lesion in the Larynx.

- Surgical excision should be offered to confirm the diagnosis and to exclude malignancy.

- MRI scan of the neck can be considered to ascertain the lateral aspect of the lesion into the laryngeal ventricle and to rule out other lesions in the laryngeal area.

- Long term follow-up is essential to watch out for recurrence.

\section{References}

1. Haemel A, Gnepp DR, Carlsten J, Robinson-Bostom L. Heterotopic salivary gland tissue in the neck. J Am Acad Dermatol. 2008;58(2):251-6.

2. Enoz M, Suoglu Y. Salivary gland choristoma of the middle ear. Laryngoscope. 2006;116(6):1033-4.

3. Tatter SB, Edgar MA, Klibanski A, Swearingen B. Symptomatic salivaryrest cyst of the sella turcica. Acta Neurochir (Wien). 1995;135(3-4):150-3.

4. Afanas'ev VV, Starodubtsev VS. Salivary gland heterotopia in the bone tissue of the mandible. Stomatologiia (Mosk). 1995;74(2):69-70.

5. Brannon RB, Houston GD, Wampler HW. Gingival salivary gland choristoma. Oral Surgery, Oral Med Oral Pathol. 1986;61(2):185-8.

6. Som P. The current embryology of the foregut and its derivatives. 2019.

7. Wise JB, Sehgal K, Guttenberg M, Shah UK. Ectopic salivary tissue of the tonsil: A case report. Int J Pediatr Otorhinolaryngol. 2005;69(4):567-71.
8. Edwards PC, Bhuiya T, Kahn LB, Fantasia JE. Salivary heterotopia of the parathyroid gland: A report of two cases and review of the literature. Oral Surgery, Oral Med Oral Pathol Oral Radiol Endodontol. 2005;99(5):590-3.

9. Kruk-Zagajewska A, Manasterski J, Gładysz J. Heterotopic salivary gland imitating laryngeal cyst. Otolaryngol Pol. 1999;53(5):623-5.

10. Yamanka J. Heterotopic salivary gland of the larynx. Larynx. 2000;12:1.

11. Kempf HG, Strkel S. Choristom des Taschenbandes. HNO. 2005;53(4):3613.

12. Yamaguchi S, Saegusa H, Aino I, Nakamura T, Komachi TMT. Case of heterotopic salivary gland of the larynx. Otolaryngol Head Neck Surg. 2008;80:553-6.

13. Yılmaz R, Bedir R, Şehitoğlu İ, Dursun E. Salivary gland choristoma of the larynx. Balkan Med J. 2017;34(3):288-9.

14. Tajima S, Yamauchi K, Higo R, Ikeda K. A case of ectopic salivary gland of the larynx. Auris Nasus Larynx. 2018;45(3):633-6.

15. Valentino W, Paknezhad H, Sataloff RT. Heterotopic salivary gland tissue in the larynx. Ear Nose Throat J. 2020;99(8):NP84-5.

16. Cannon D, Szabo S, Flanary V. Heterotopic salivary tissue. Am J Otolaryngology. 2012;33(4):493-6.

17. Karatayli-Ozgursoy S, Bishop JA, Hillel AT, Akst LM, Best SR. Malignant salivary gland tumours of the larynx: A single institution review. Tumori maligni delle ghiandole salivari della laringe: Un'unica review istituzionale. Acta Otorhinolaryngol Ital. 2016;36(4):289-94.

18. Ganly I, Patel SG, Coleman M, Ghossein R, Carlson D, Shah JP. Malignant minor salivary gland tumors of the larynx. Arch Otolaryngol Head Neck Surg. 2006;132(7):767-70.

19. Nielsen TK, Bjørndal K, Krogdahl A, Primdahl H, Kristensen CP, Andersen E, et al. Salivary gland carcinomas of the larynx: A national study in Denmark. Auris Nasus Larynx. 2012;39(6):611-4.

20. Prgomet D, Bilić M, Bumber Z, Manojlović S, Katić V. Mucoepidermoid carcinoma of the larynx: Report of three cases. J Laryngol Otol. 2003;117(12):998-1000. 